\title{
Reversible Left Ventricular Systolic Dysfunction Secondary to Pazopanib
}

Kushani Gajjar $^{1}$, Kathir Balakumaran ${ }^{2}$, Agnes S. Kim ${ }^{2}$

1. Internal Medicine, University of Connecticut Health Center, Farmington, USA 2. Cardiology, University of Connecticut Health Center, Farmington, USA

Corresponding author: Kathir Balakumaran, balakumaran@uchc.edu

\section{Abstract}

Pazopanib is a tyrosine kinase inhibitor used for the treatment of advanced renal cell carcinoma and advanced soft tissue sarcoma. We describe a case report of a patient with spindle cell sarcoma who developed severe left ventricular systolic dysfunction after starting pazopanib therapy with subsequent recovery of left ventricular ejection fraction upon stopping therapy.

Categories: Cardiology, Internal Medicine, Oncology

Keywords: pazopanib, cardio-oncology, oncology, cardiomyopathy, cardiotoxicity, tyrosine kinase inhibitors, vascular-endothelial growth factor

\section{Introduction}

Pazopanib is a vascular endothelial growth factor and tyrosine kinase inhibitor (VEGF-TKI) used in the treatment of advanced renal cell carcinoma (RCC) and advanced soft tissue sarcoma. They are known to cause adverse cardiovascular effects including hypertension, cardiomyopathy, thromboembolism and myocardial ischemia. We describe a case report of a patient with spindle cell sarcoma who developed severe left ventricular systolic dysfunction after starting Pazopanib therapy with subsequent recovery of left ventricular ejection fraction (LVEF) upon stopping therapy.

\section{Case Presentation}

A 49-year-old man with a history of spindle cell sarcoma status post left arm below-elbow amputation developed recurrence of the sarcoma three years post amputation. He was found to have metastasis of cancer to the lungs on staging (Figure 1) and received three cycles of Doxorubicin and Olaratumab followed by wide excision of the soft tissue tumor.

Received 08/17/2018

Review began 09/06/2018 Review ended 10/25/2018 Published 10/29/2018

(c) Copyright 2018

Gajjar et al. This is an open access article distributed under the terms of the Creative Commons Attribution License CC-BY 3.0., which permits unrestricted use, distribution, and reproduction in any medium, provided the original author and source are credited.

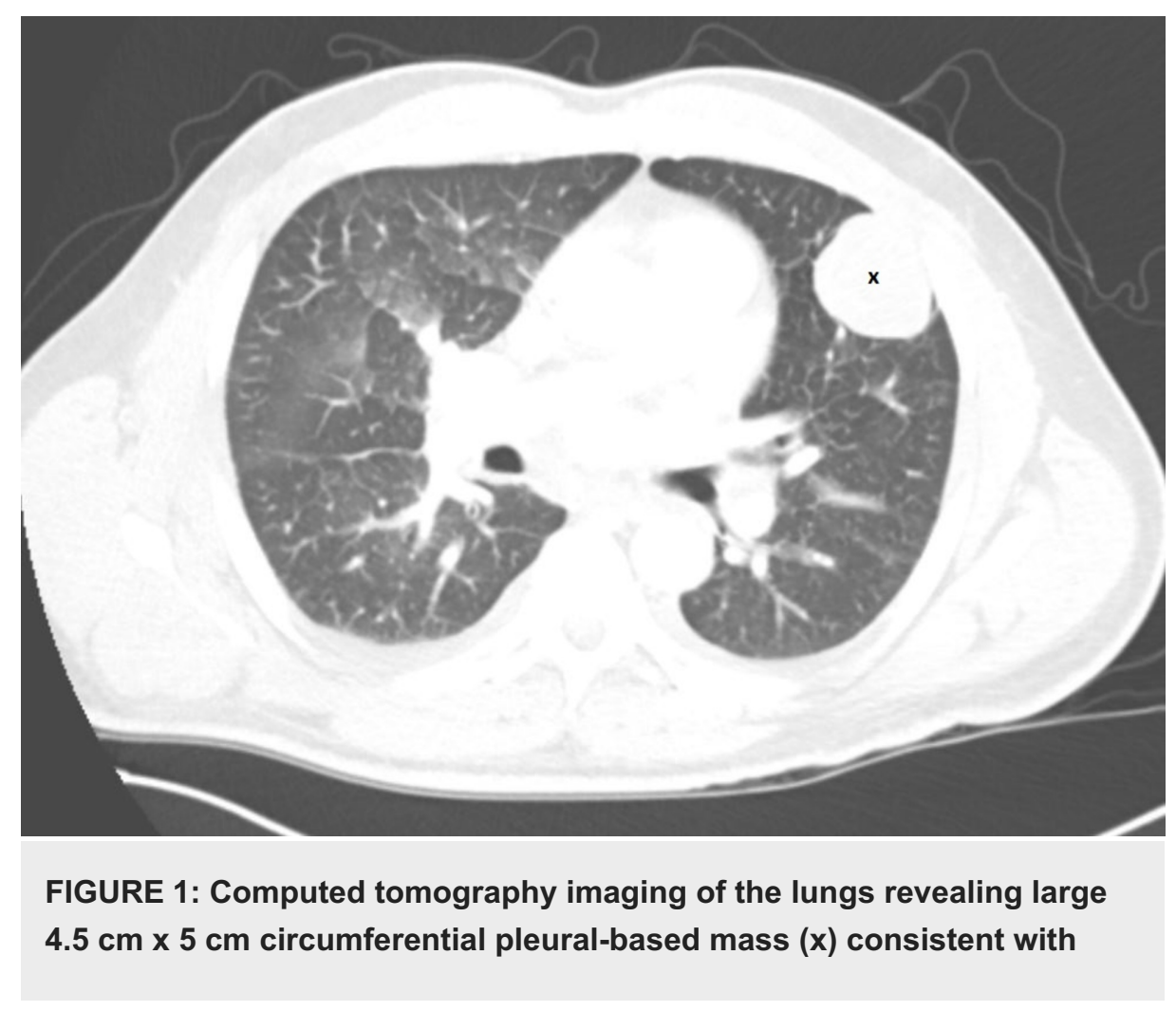




\section{Cureus}

metastatic sarcoma.

He underwent a transthoracic echocardiogram (TTE) six months after completion of Doxorubicin therapy, and his LVEF was found to be normal at that time. Unfortunately, he continued to have progression of pulmonary metastasis and hence was initiated on Pazopanib, which is a second line therapy for advanced soft tissue sarcomas. Shortly after initiation of therapy, the patient started developing palpitations, shortness of breath on exertion and chest tightness. His symptoms progressively worsened, until he suffered a syncopal episode 10 days after initiation of Pazopanib. On admission to the hospital, the patient's physical examination was unremarkable. The laboratory data was remarkable for an elevated troponin I to $0.09 \mathrm{ng} / \mathrm{dl}$ on admission. His electrocardiogram (ECG) revealed nonspecific ST segment changes (Figure 2).

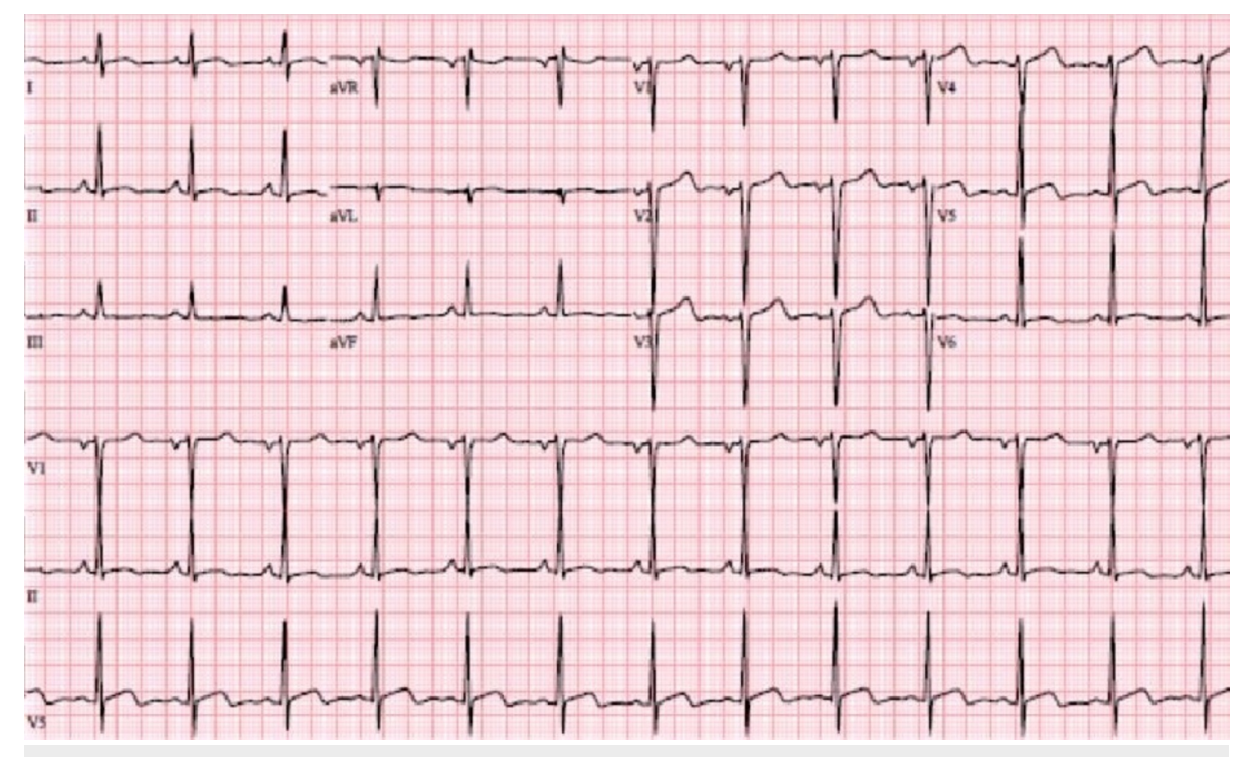

FIGURE 2: Admission electrocardiogram.

As part of the workup for his syncope, he underwent a TTE, which revealed an LVEF of $10 \%$ to $15 \%$ with severe diffuse hypokinesis, right ventricular systolic dysfunction with normal biventricular chamber sizes. He subsequently underwent cardiac catheterization which revealed normal coronary anatomy (Figure 3). 


\section{Cureus}
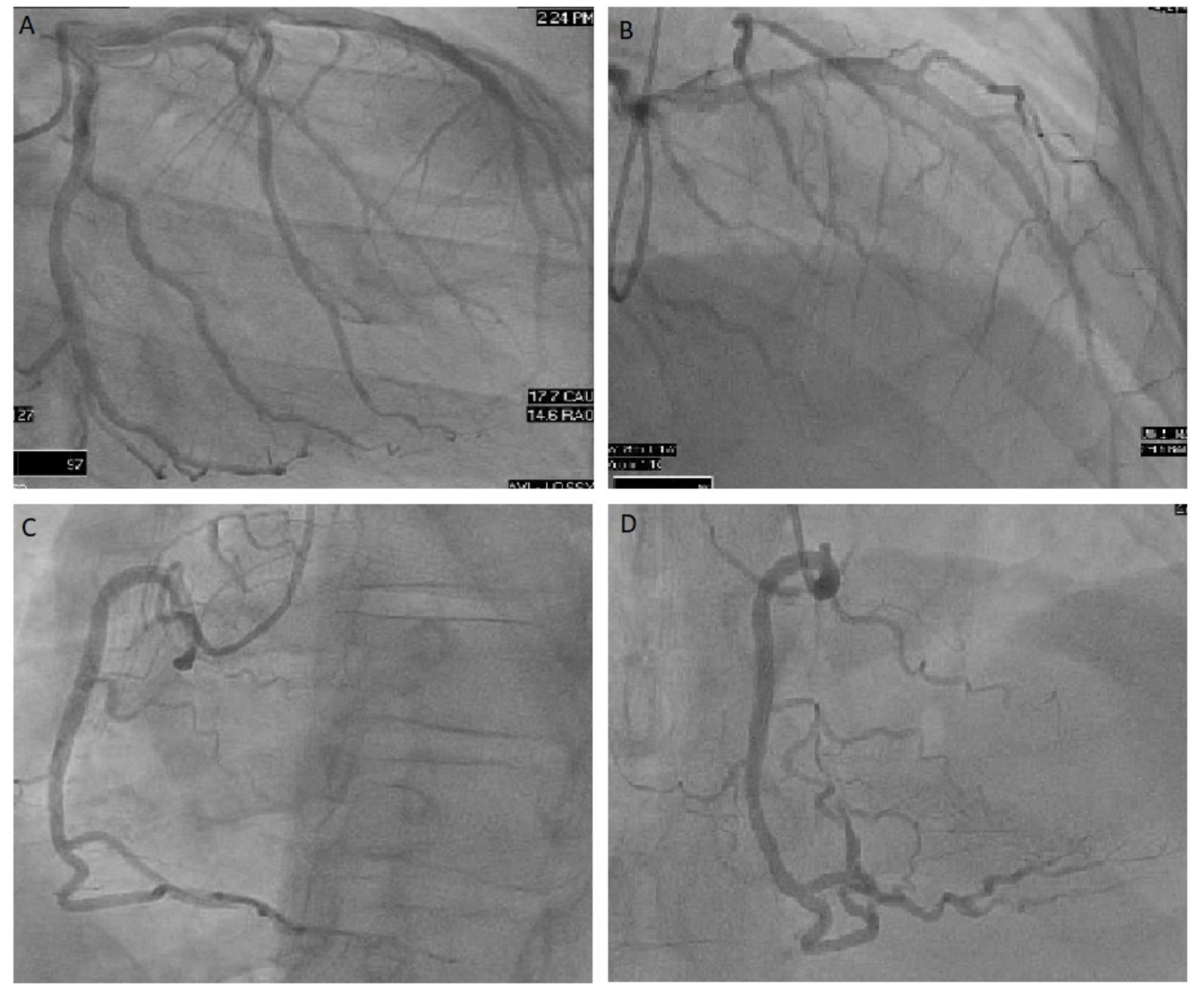

\section{FIGURE 3: Coronary angiography. (A) Left anterior oblique view of revealing patent left coronary vasculature. (B) Right anterior oblique cranial view revealing patent left coronary vasculature. (C) Right anterior oblique view revealing patent right coronary vasculature. (D) Right anterior oblique view revealing patent right coronary vasculature.}

He was initiated on guideline directed medical therapy with a beta blocker and angiotensin converting enzyme inhibitor and discharged with cardiology and oncology follow-up. His Pazopanib was stopped on discharge. The patient subsequently underwent repeat TTE six weeks from discharge, which revealed recovery of LVEF to 40 to $45 \%$ with normal cavity size and mild diffuse hypokinesis. A repeat TTE three months afterwards revealed an LVEF 45 to $50 \%$. He was subsequently started on immunotherapy with Ipilimumab and Nivolumab combination therapy.

\section{Discussion}

In RCC trials, myocardial systolic dysfunction with Pazopanib has been reported to be about 13\% [1]. A meta-analysis of congestive heart failure (CHF) with VEGF-TKI shows a relative risk of all grade and highgrade CHF for the VEGF-TKI vs. no VEGF-TKI arms was 2.69 and 1.65, respectively [2]. In 362 Pazopanibtreated patients, a $1 \%$ incidence of symptomatic heart failure (HF) and $9 \%$ incidence of an absolute left ventricular ejection fraction decline of $15 \%$ or greater was observed [3]. Higher rates were described in a meta-analysis that included three trials $(n=314)$ and found an HF incidence rate of $6.1 \%$ [4]. There have been few case reports of heart failure induced by Pazopanib including apical ballooning and rapid fatal cardiac decompensation [5-8].

Pazopanib has a multimodal mechanism of action, including inhibiting cell surface VEGF and plateletderived growth factor (PDGF) receptors. VEGF plays a central role both in maintaining a well-vascularized myocardium and in developing a robust neovascular response to chronic ischemic changes [9]. In a rabbitmodel of left ventricular hypertrophy, promoting capillary growth with VEGF reduces apoptosis, preserves myocardial contractile function, and delays the onset of heart failure [10]. Moreover, PDGF expressed in cardiomyocytes, also a target of Pazopanib, has been demonstrated to exert a cardioprotective angiogenic function [11]. This thus suggests that VEGF and PDGF receptor inhibition could induce cardiomyocyte apoptosis and prevent cardiac remodeling, resulting in ventricular dysfunction. A recent study in 2017 suggests that the cellular targets likely to be involved in cardiac failure with protein kinase inhibitors may be ABL1 and ABL2 tyrosine kinases (Abelson Murine Leukemia Viral Oncogene Homolog) [12]. There is some evidence to suggest that TKI interruption along with optimal guideline-directed cardiovascular treatment leads to improvement in cardiac status and such patients can be eligible to resume TKI therapy [11]. 
Additionally, cardiotoxicity and subsequent left ventricular systolic dysfunction is a known complication of anthracyclines, however most cardiotoxicity after anthracycline-containing therapy occurs within the first year and is associated with anthracycline dose and LVEF at the end of treatment [13]. Our patient had normal LVEF six months after completion of anthracycline therapy and hence we believe that his acute heart failure was in the setting of VEGF-TKI administration. He also subsequently recovered his LVEF upon stopping the VEGF-TKI. The PALETTE trial showed a $1 \%$ rate of symptomatic left ventricular systolic dysfunction in people treated with Pazopanib, while $99 \%$ of patients had received anthracyclines [1]. This again supports the hypothesis that Pazopanib causes cardiotoxicity independent of prior exposure to anthracyclines.

\section{Conclusions}

We believe this case report will add to the available literature about this potentially life-threatening complication associated with VEGF-TKI therapy while demonstrating the potential reversibility of cardiotoxicity with cessation of therapy. We summarize that close monitoring of cardiac function on Pazopanib and other VEGF-TKI inhibitors is necessary. These patients need close follow-up in specialized cardiology-oncology clinics and monitoring echocardiograms while on these medications. With improving understanding of the genetic variations involved in adverse cardiac events especially heart failure, it might be possible to use this knowledge to screen which patients are at a higher risk for these complications.

\section{Additional Information}

\section{Disclosures}

Human subjects: Consent was obtained by all participants in this study. Conflicts of interest: In compliance with the ICMJE uniform disclosure form, all authors declare the following: Payment/services info: All authors have declared that no financial support was received from any organization for the submitted work. Financial relationships: All authors have declared that they have no financial relationships at present or within the previous three years with any organizations that might have an interest in the submitted work. Other relationships: All authors have declared that there are no other relationships or activities that could appear to have influenced the submitted work.

\section{References}

1. van der Graaf WT, Blay JY, Chawla SP, et al.: Pazopanib for metastatic soft-tissue sarcoma (PALETTE): a randomised, double-blind, placebo-controlled phase 3 trial. Lancet. 2012, 379:1879-1886. 10.1016/S01406736(12)60651-5

2. Ghatalia P, Morgan CJ, Je Y, Nguyen PL, Trinh QD, Choueiri TK, Sonpavde G: Congestive heart failure with vascular endothelial growth factor receptor tyrosine kinase inhibitors. Crit Rev Oncol Hematol. 2015, 94:228-237. 10.1016/j.critrevonc.2014.12.008

3. Motzer RJ, Hutson TE, Cella D, et al.: Pazopanib versus sunitinib in metastatic renal-cell carcinoma . N Engl J Med. 2013, 369:722-731. 10.1056/NEJMoa1303989

4. Qi WX, Shen Z, Tang LN, Yao Y: Congestive heart failure risk in cancer patients treated with vascular endothelial growth factor tyrosine kinase inhibitors: a systematic review and meta-analysis of 36 clinical trials. Br J Clin Pharmacol. 2014, 78:748-762. 10.1111/bcp.12387

5. Abdallah AO, Vallurupalli S, Kunthur A: Pazopanib- and bevacizumab-induced reversible heart failure in a patient with metastatic renal cell carcinoma: a case report. J Oncol Pharm Pract. 2016, 22:561-565. 10.1177/1078155215585189

6. Van Marcke C, Ledoux B, Petit B, Seront E: Rapid and fatal acute heart failure induced by pazopanib . BMJ Case Rep. 2015, 10.1136/bcr-2015-211522

7. White AJ, LaGerche A, Toner GC, Whitbourn RJ: Apical ballooning syndrome during treatment with a vascular endothelial growth factor receptor antagonist. Int J Cardiol. 2009, 131:92-94. 10.1016/j.ijcard.2007.07.066

8. Friehs I, Barillas R, Vasilyev NV, Roy N, McGowan FX, del Nido PJ: Vascular endothelial growth factor prevents apoptosis and preserves contractile function in hypertrophied infant heart. Circulation. 2006, 114:290-295. 10.1161/CIRCULATIONAHA.105.001289

9. Deuse T, Peter C, Fedak PW, et al.: Hepatocyte growth factor or vascular endothelial growth factor gene transfer maximizes mesenchymal stem cell-based myocardial salvage after acute myocardial infarction. Circulation. 2009, 120:247-254. 10.1161/CIRCULATIONAHA.108.843680

10. Edelberg JM, Lee SH, Kaur M, et al.: Platelet-derived growth factor-AB limits the extent of myocardial infarction in a rat model: feasibility of restoring impaired angiogenic capacity in the aging heart. Circulation. 2002, 105:608-613. 10.1161/hc0502.103672

11. Schmidinger M, Zielinski CC, Vogl UM, et al.: Cardiac toxicity of sunitinib and sorafenib in patients with metastatic renal cell carcinoma. J Clin Oncol. 2008, 26:5204-5212. 10.1200/JCO.2007.15.6331

12. Patras de Campaigno E, Bondon-Guitton E, Laurent G, Montastruc F, Montastruc J-L, Lapeyre-Mestre M, Despas F: Identification of cellular targets involved in cardiac failure caused by PKI in oncology: an approach combining pharmacovigilance and pharmacodynamics. Br J Clin Pharmacol. 2017, 83:1544-1555. 10.1111/bcp. 13238

13. Cardinale D, Colombo A, Bacchiani G, et al.: Early detection of anthracycline cardiotoxicity and improvement with heart failure therapy. Circulation. 2015, 131:1981-1988.

10.1161/CIRCULATIONAHA.114.013777 